\title{
Age-Related Changes in the Gross Morphology and Morphometry of the Testis and Epididymis of the African Greater Cane Rat (Thryonomys swinderianus)
}

\author{
Jamiu Oyewole Omirinde ${ }^{1, a, *}$, Samuel Gbadebo Olukole ${ }^{2, b}, B^{2}$ ankole Olusiji Oke \\ ${ }^{I}$ Department of Veterinary Anatomy, Faculty of Veterinary Medicine, University of Jos, Jos, Plateau State, Nigeria. \\ ${ }^{2}$ Department of Veterinary Anatomy, Faculty of Veterinary Medicine, University of Ibadan, Ibadan, Oyo State, Nigeria.
} *Corresponding author

\section{A R T I C L E I N F O A B S T R A C T}

Research Article

This study evaluated age-related changes in the gross morphology and morphometry of the testis and epididymis of the African Greater Cane Rat (AGCR). Twenty pathogen-free cane rats used for this study were randomly divided into 4 groups; Group I - prepubertal ( $\leq 4$ months), Group II pubertal ( $>4 \leq 12$ months), Group III - adult ( $>12 \leq 30$ months), and Group IV - aged ( $>30$ months)

Received : 05/10/2020

Accepted : 01/12/2020 of 5 animals each. On day 8th of acclimatization, testis and epididymis were harvested from sedated cane rat, described grossly and standard morphometric parameters (length, width, circumference, weight, and relative weight) determined. Gross morphological observations in the testes of all the different age categories showed similar characteristically cream to milky-white coloration and ellipsoidal shape. The epididymis in the different AGCR group uniquely presents the same inverted S-shaped outline, loose attachment to the testis, and less distinct division into caput, corpus, and cauda segments. Testicular and epididymal morphometric parameters were significantly reduced in

Keywords:

Testis

Epididymis

Gross morphometry

Age-related changes

Thryonomys swinderianus the prepubertal cane rat relative to other groups. The parameters consistently displayed an agedependent increment with the advancing age of the animal. In conclusion, this study has shown that both testicular and epididymal gross morphometrics increase with age advancement and perhaps might be linked to the varying functional reproductive status of the different age groups of the African greater cane rat.

\section{Introduction}

The African Greater Cane Rat (AGCR) is the secondlargest rodent of African origin after the Cape porcupine (Skinner and Smithers, 1990). It is seen in abundance in the several savanna biotic zones of sub-Sahara Africa. (Happold, 1987; Monadjem et al., 2015). The AGCR is reputed for impacting the economic growth of a number of countries in West Africa where its meat is expensively sold and preferentially demanded over other available wild rodents (Baptist and Mensah, 1986; Ntiamoa-Baidu, 1998; Asibey and Addo, 2000). This increased demand for its meat and the need to mitigate the existing acute shortage of protein in the face of increasing demand for livestock products account for its massive domestication for increased production in Nigeria and several other African countries (Jori et al., 1995; Adu et al., 2005; Adekola and Ogunsola, 2009).

The paired mammalian testis is an oval structure that is situated in a specialized pouch of skin called the scrotum (Banks, 1993). The testis has both exocrine (produce spermatozoa) and endocrine (secrete gonadal hormones) functions (Monteiro et al., 2012). In most vertebrate animals, the testis is enveloped by a testicular capsule tissue whose morpho-architecture permits the entrance and exit of blood vessels and nerves into the parenchyma of the organ (Aire and Ozegbe, 2007). The cane rat testis has an ovoid shape, varying colorations ranging between milk to creamy white colors and a small testiculo-somatic weight when compared to other rodents of African origin (Olukole et al., 2009).

The Epididymis is a single convoluted duct that is otherwise referred to as ductus epididymis (Akbarsha et al., 2015). It connects the efferent ducts with the vas deferens (Singh, 2011). It is situated subjacent to the testis on each side and adheres to the latter on the medial side via connective tissue. Distally, it is secured by the ligament of the tail of the epididymis and the epididymal fat cushion (Dyce et al., 2002). In different mammals, the ductus epididymis measure between 3-80 meters. It is a well- 
convoluted duct that is enclosed by a thin capsular covering that ends up forming the epididymis (Akbarsha et al., 2015). The epididymal duct in the adult cane rat has been found to assume an inverted S-shaped outline with varying coloration ranging between pinkish to creamy white colors and had an inconspicuous gross anatomical division into segments (Adebayo and Olurode, 2010).

Gross morphological studies of organs especially the reproductive organs provide basic information regarding the normal organs parenchymal architecture while morphometry estimates dimensions, amount of tissues, and activities in progress (Gofur, 2015). The detailed understanding of age-related changes in testicular and epididymal morphology and morphometry and their functional implications as it pertains to male grasscutter reproductive biology is highly essential owing to the fact that in cane rat breeding, only one male is used for mating several females (Soro et al., 2014).

Available research reports on the male reproductive biology of the AGCR (Aire and Van der Merwe, 2003; Adebayo et al., 2009; Adebayo and Olurode, 2010; Adebayo et al., 2014a and b, 2015, 2016, 2019; Olukole et al., 2009, 2010) focused mainly on the adult without any information on age-related changes in the gross morphology and morphometrics of reproductive organs of the animal. This study was therefore designed to investigate age-related changes in the gross morphology and morphometrics of the testis and epididymis of the AGCR. Hence, this study hopes to fill this gap, and results emanating from this study would constitute useful baseline data to the rodent researcher, wildlife veterinarian, and cane rat farmers.

\section{Materials and Methods}

\section{Experimental Animals/Design}

Twenty (20) cane rats procured from Pavemgo cane rat farm, Ibereko, Badagry, Lagos state were used for this study. Records relating to the birth of the rats were obtained at the point of purchase. They were acclimatized and fed dry corn feeds daily and water ad libitum for 7days in the Experimental Animal Unit of Faculty of Veterinary Medicine, University of Ibadan. The cane rats used for this study were ethically cleared by the University of Ibadan Animal Care and Use Research Ethics Committee Review (UI-ACUREC) and assigned UI-ACUREC/18/0120.

Based on the grouping earlier reported in our previous study (Omirinde et al., 2019), the cane rats were randomly divided into four (4) groups of five (5) animals each; prepubertal (1-4 months), pubertal (5-11 months), adult (12- 30 months) and aged (>30 months).

\section{Anesthesia and Organ Excision}

On the 8th day of the stabilization, cane rats were sedated using intramuscular injection of xylazine and ketamine combinations (20mg/kg: $80 \mathrm{mg} / \mathrm{kg}$ bdwt; respectively). Thereafter, the abdominal cavity was accessed using the approach of Olukole et al. (2010). The testes as well as their attached epididymis were excised via the incision on the tunica vaginalis and then placed in petrish dishes containing normal saline to prevent organ dessication.

\section{Determination of Testicular and Epididymal Biometric Parameters}

Prior to the dissection of the anesthetized AGCR, the individual body weight of each rat was taken using a kitchen scale. Consistently the weight of the right testis and epididymis of the different groups of AGCR was determined using digital Microvar weighing balance and biometric parameters were measured using digital vernier caliper (Mitutoyo Company, Japan). The relative weights of each of the organs were calculated with the use of the formulae below:

$$
\text { Relative Weight }(\%)=\frac{\text { Weight of Organ }(\mathrm{g})}{\text { Weight of animal }(\mathrm{g})} \times 100
$$

Gross testicular and epididymal biometric parameters such as length, width, and circumference were obtained using the description of Olukole et al. (2009). The length was taken as the distance between the anterior to the posterior borders, the width as the distance between the lateral and medial borders, and the circumference as the total distance obtained when the testis is encircled at its mid-portion with a calibrated nylon tape.

\section{Statistical Analysis}

Data obtained were expressed as mean \pm SE. Using GraphPad Prism Version 4.00 for Windows, GraphPad Software (GraphPad Prism, 2003), one-way analysis of variance (ANOVA) was used to evaluate significant differences across groups and the values of $\mathrm{P}<0.05$ was considered significant. A Turkey post hoc test was further used to evaluate the significant differences between groups.

\section{Result}

Testicular and Epididymal Gross Appearances in Different Age Groups of African Greater Cane Rat

The paired testes were suspended in the scrotal sac situated caudo-ventral to the penis. The coloration and shape of the testes are characteristically cream to milkywhite and ellipsoidal respectively. The testes are secured at the cranial pole by the mesofurniculus fold (an homologue of the visceral lamina of the vaginal layer enveloping the spermatic cord). The testes are adhered loosely to the epididymis at the epididymal border by a ligament. The testes across all age groups are grossly covered by a transparent capsule, the tunica albuginea (Figure 1A\&B).

Unlike the testes, the epididymis of all AGCR has pinkish to creamy white coloration, an inverted S-shaped outline that is loosely attached to the testis (T). Grossly, the epididymis is less distinctly divided into caput (a), corpus (b), and cauda (c) segments. The caput and corpus segments bear visible convolutions relative to the caudal segment (Figure 2A\&B).

Age-Related Changes in The Biometric and Gross Morphometric Parameters of the Testis and Epididymis of the African Greater Cane Rat

The details of the testicular and epididymal biometric parameters are summarized in Table 1 . The body weights (BW) of the AGCR used for this study significantly increase $(\mathrm{P}<0.05)$ as age advances with the extremes of BW $(0.75 \pm 0.14 ; 4.63 \pm 0.24 \mathrm{~kg})$ observed in the pre- 
pubertal and aged respectively. Testicular weight was significantly reduced $(\mathrm{P}<0.05)$ in the pre-pubertal rat compared to other groups. Also, testicular weights markedly increase $(\mathrm{P}<0.05)$ in both the adult and aged testes when compared to others. The testicular weight appears to increase with the age of the animal.

Regarding the relative testicular weight (RTW) or testiculosomatic index, significant decrease $(\mathrm{P}<0.05)$ was observed in the pre-pubertal rat when compared to others. There was no significant difference $(\mathrm{P}>0.05)$ in the RTW from pubertal onwards, although, an insignificant increase
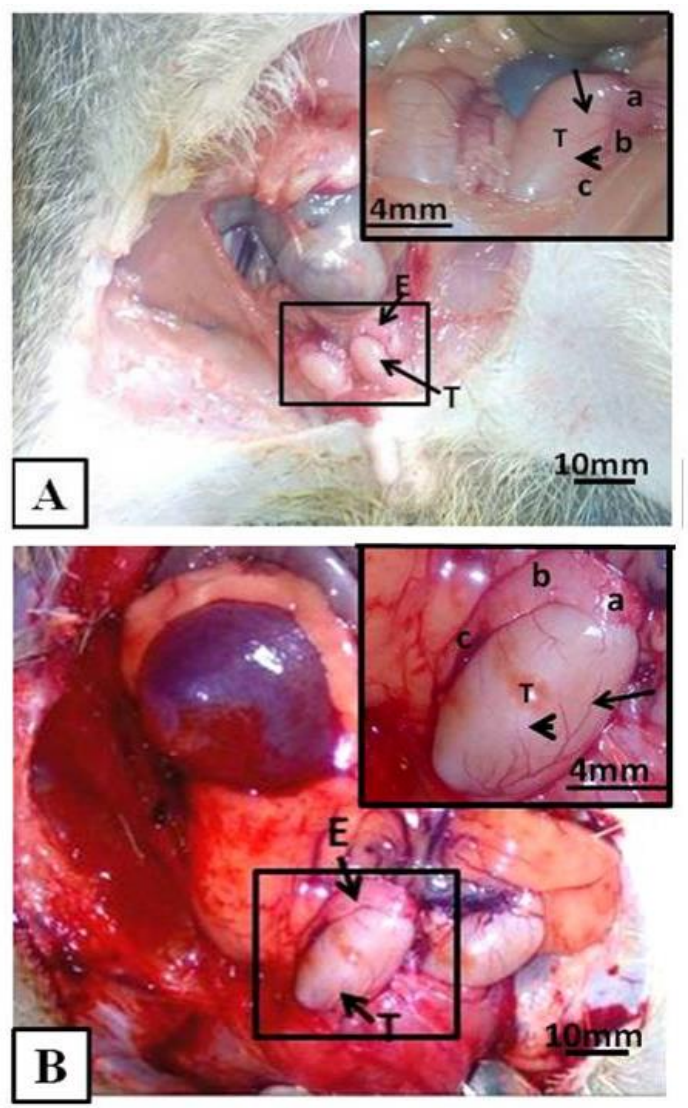

Figure 1. Photographs of the male reproductive organs in the cane rat in-situ.

A. Pre-pubertal B. Adult. Note the creamy white ellipsoidal testes (T), the inverted S-shaped epididymis (E) and its caput (a), corpus (b) and cauda (c) segments. Also observe the conspicuous albuginea vessels (arrow) and transparent tunica albuginea (arrow-head)
( $\mathrm{P}>0.05)$ was seen in the adult AGCR when compared to others. Similarly, testicular length (TL) as well as testicular width (TW) was markedly reduced in the pre-pubertal rat relative to others. However, significantly increased $(\mathrm{P}<0.05)$ TL and TW values were seen in both adult and aged AGCR when compared to others. For testicular circumference (TC), significantly decreased $(\mathrm{P}<0.05)$ values were observed in the prepubertal rat compared to others. There was no significant difference $(\mathrm{P}>0.05)$ in the TC of pubertal AGCR onwards, though, an insignificant increase $(\mathrm{P}>0.05)$ exists in the value of TC in adult AGCR relative to others.
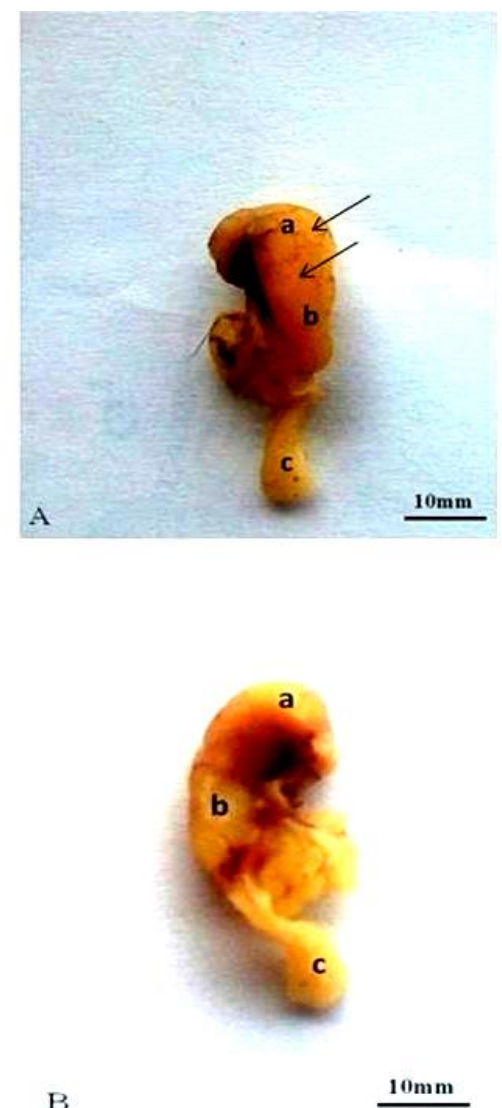

Figure 2. Photographs of the epididymis of the African Greater Cane Rat.

A. Lateral view B. medial view. Note the inverted S-shaped epididymis and its caput (a), corpus (b) and cauda (c) segments. Also, observe the visible convolutions (arrows) within caput and corpus segments

Table 1. Age-related changes in the biometric and morphometric parameters of the testis and epididymis of African Greater Cane Rat

\begin{tabular}{|c|c|c|c|c|}
\hline Bio-morphometric Parameters & PRE & PUB & ADULT & AGED \\
\hline Body Weight (kg) & $0.75 \pm 0.14^{\mathrm{a}}$ & $1.95 \pm 0.08^{\mathrm{b}}$ & $3.08 \pm 0.15^{\mathrm{c}}$ & $4.63 \pm 0.24^{\mathrm{d}}$ \\
\hline Testi. Weight (g) & $0.13 \pm 0.04^{\mathrm{a}}$ & $0.83 \pm 0.09^{b}$ & $1.55 \pm 0.13^{\mathrm{c}}$ & $1.73 \pm 0.05^{\mathrm{c}}$ \\
\hline Rel. Testi. Wt. (\%) & $0.02 \pm 0.00^{\mathrm{a}}$ & $0.04 \pm 0.00^{\mathrm{b}}$ & $0.05 \pm 0.00^{\mathrm{b}}$ & $0.04 \pm 0.00^{\mathrm{b}}$ \\
\hline Testi. Length (mm) & $12.50 \pm 0.80^{\mathrm{a}}$ & $20.00 \pm 0.31^{\mathrm{b}}$ & $28.00 \pm 0.18^{c}$ & $30.03 \pm 0.20^{c}$ \\
\hline Testi. Width (mm) & $5.70 \pm 0.70^{\mathrm{a}}$ & $9.00 \pm 0.10^{\mathrm{b}}$ & $14.00 \pm 0.60^{\mathrm{c}}$ & $11.30 \pm 0.88^{c}$ \\
\hline Testi. Circum (mm) & $15.00 \pm 0.12^{\mathrm{a}}$ & $30.30 \pm 0.18^{\mathrm{b}}$ & $38.00 \pm 0.15^{\mathrm{b}}$ & $36.80 \pm 0.12^{\mathrm{b}}$ \\
\hline Epid. Weight (g) & $0.06 \pm 0.00^{\mathrm{a}}$ & $0.28 \pm 0.00^{\mathrm{b}}$ & $0.35 \pm 0.00^{\mathrm{b}}$ & $0.50 \pm 0.00^{\mathrm{c}}$ \\
\hline Rel. Epid. Wt. (\%) & $0.01 \pm 0.00$ & $0.01 \pm 0.00$ & $0.01 \pm 0.00$ & $0.01 \pm 0.00$ \\
\hline Epi. Length (mm) & $13.30 \pm 0.14^{\mathrm{a}}$ & $20.55 \pm 0.27^{\mathrm{a}}$ & $34.30 \pm 0.49^{\mathrm{b}}$ & $40.25 \pm 0.36^{\mathrm{b}}$ \\
\hline Cap. Width (mm) & $3.25 \pm 0.75^{\mathrm{a}}$ & $8.00 \pm 0.18^{\mathrm{b}}$ & $11.00 \pm 0.13^{\mathrm{c}}$ & $12.25 \pm 0.63^{\mathrm{c}}$ \\
\hline Cor. Width (mm) & $1.75 \pm 0.48^{\mathrm{a}}$ & $6.75 \pm 0.85^{b}$ & $9.00 \pm 0.13^{b}$ & $10.00 \pm 0.71^{\mathrm{b}}$ \\
\hline Cau. Width (mm) & $1.43 \pm 0.37^{\mathrm{a}}$ & $5.50 \pm 0.910^{\mathrm{b}}$ & $7.88 \pm 0.89^{b}$ & $9.25 \pm 0.32^{\mathrm{b}}$ \\
\hline
\end{tabular}

Values with different alphabet superscripts in the row are significantly different, PRE- Pre-pubertal, PUB - Pubertal, Testi -Testicular, Rel - Relative, Wt - Weight, Cap - Caput, Cor - Corpus, Cau -Cauda 
Epididymal weight (EW), epididymal length (EL), caput $(\mathrm{CW})$, corpus $(\mathrm{CPW})$ and cauda (CAW) widths present similar trends of significantly decreased values in the pre-pubertal rat compared to other groups. There was no significant difference $(\mathrm{P}>0.05)$ in the values of these parameters from pubertal to aged, although, an insignificant increase $(\mathrm{P}>0.05)$ in their values occurs in the aged AGCR. In addition, there was no significant difference $(\mathrm{P}>0.05)$ in the relative epididymal weight in all the AGCR groups.

\section{Discussion}

The characteristic cream to milky-white coloration and ellipsoidal shape of the testes observed in the different age groups of the African Greater Cane Rat is consistent with the reports of Olukole et al. (2009) on the testicular gross morphologic appearance in the mature adult cane rat. The progressive age-related increase in the testicular weight and the relative testicular weight with maximum testiculosomatic weight value displayed by the adult group of cane rat implies that with the advancement in age, testicular weights increase with increasing body weight. The rise in the values of these indices could probably be related to the functional reproductive status of the testicular parenchymal tissue from pubertal age to the aged. The range of the extremes of the relative weights in pubertal and adult further tallies with the earlier report of Olukole et al. (2009) on the smaller nature of cane rat testes relative to their body size.

The evaluation of testicular morphometric parameters (length, width, and circumference) most especially the and the onset of active spermatogenesis (Bongso et al., 1982). Therefore, the significant age-dependent increase in testicular morphometric parameters could also be attributed to morphological compensation with the varying reproductive functional activities with advancing age. The findings on the weight and morphometric parameters concur with reports from similar age-related studies on the buck by Nishimura et al. 2000 and Dhabale (2007).

The inverted S-shaped appearance of the epididymis, the visible numerous convolutions of the caput and corpus epididymal segments, as well as the slight variations in the coloration of the segments observed in all the different age groups of Thryonomis swinderianus, is in agreement with the features of epididymis documented by Adebayo et al. (2010) in the matured adult greater cane rat.

The age-dependent increase in the epididymal weight together with the uniform epididymal somatic weight $(0.01$ percentage body weight) seen across the different age groups of the cane rat could substantiate the probable compensatory weight gain with the advancement in age. However, the postulated theory could not explain the reason for the non-significant difference in the relative epididymal weights across the studied animal. The epididymal length and width were also observed to increase with age thereby conforming to the pattern earlier described for the testicular biometric parameters. It is important to mention that the width of the caput segment relative to other segments was markedly longer in all the groups and this could be connected to the massive convolution of the caput segment. The morphometric parameters in this study corroborate the finding of Gupta and Singh (1988a).

This study has shown that both testicular and epididymal gross morphometrics increase with age advancement and perhaps might be linked to the varying functional reproductive status of the different age groups of African Greater Cane Rats.

\section{Acknowledgments}

The authors are grateful to Dr Lanipekun D.O of the Department of Veterinary Anatomy for his assistance during the bench work.

\section{References}

Adebayo AO, Oke BO, Akinloye AK. 2009. The gross morphometry and histology of the male accessory sex glands in the greater cane rat (Thryonomys swinderianus Temminck). J. Vet. Anat. 2 (2): 41-51. doi: 10.21608/ JVA.2009.42308

Adebayo AO, Olurode SA. 2010. The morphology and morphometry of the epididymis in the greater cane rat (Thryonomys swinderianusTemmincks). Folia Morphol. 69 (4): 246-252.

Adebayo AO, Akinloye AK, Olukole SG, Ihunwo AO, Oke BO. 2014a. Anatomical and immunohistochemical characteristics of the prostate gland in the greater cane rat (Thryonomys swinderianus). Anat. Histol. Embryol. 42 (2): 1 - 8. doi: 10.1111/ahe.12122.

Adebayo AO, Akinloye AK, Olukole SG, Oyeyemi MO, Taiwo VO, Ihunwo AO, Oke BO. 2014b. Gross histological and ultrastructural features of the bulbourethral gland in the greater cane rat (Thyonomys swinderianus). Anat. Histol. Embryol. 43 (1): 1 - 7. doi: https://doi.org/10.1111/ahe.12108.

Adebayo AO, Akinloye AK, Ihunwo AO, Oke BO. 2015. The coagulating gland in the male greater cane rat (Thryonomys swinderianus): morphological and immunohistochemical features. Folia Morphol. 74 (1): 25-32. doi: 10.5603/ FM.2015.0005.

Adebayo AO, Akinloye AK, Ihunwo AO, Taiwo VO, Oke BO. 2016. Zonal changes in the ultrastructure of the epididymal principal cell of the greater cane rat (Thryonomys swinderianus). Alexandria J. Vet. Sci. 48 (1): 99-106. doi: 10.5455/ajvs.204076.

Adebayo AO, Akinloye AK, Ihunwo AO, Taiwo VO, Oke BO. 2019. Ultrastructural studies of acrosomal formation in the male greater cane rat (Thryonomys swinderianus). J. Microsc. Ultrastruct. 7 (1): 14-8. doi: http://www.jmau.org/ text.asp?2019/7/1/14/254064.

Adekola AG, Ogunsola DS. 2009. Determinants of productivity level of commercial grasscutter farming in Oyo State. Proceeding International Conference on Global Food Crisis. 19th - 24th April, Owerri, Nigeria. pp. 15 - 21.

Adu EK, Otsyina RH, Agyei AD. 2005. The efficacy of different dose levels of albendazole for reducing fecal worm egg count in naturally infected captive grasscutter (Thryonomys swinderianus, Temminck). Livest. Res. Rural Dev. Volume 17, Article \#128. Retrieved October 3, 2020, from http://www.lrrd.org/lrrd17/11/adu17128.htm.

Aire TA, Van der Merwe M. 2003. The ductuli efferentes of the greater cane rat (Thryonomys swinderianus). Anat. Embryol. 206: 409-417. doi: 10.1007/s00429-003-0310-0.

Aire TA, Ozegbe PC. 2007. The testicular capsule and peritubular tissue of birds: morphometry, histology, ultrastructure and Immunohistochemistry. J. Anat. 210: 731-740. doi: 10.1111/ j.1469-7580.2007.00726.x. 
Akbarsha MA, Faisal K, Rasha A. 2015. The epididymis: structure and function, mammalian endocrionology and male reproductive biology. doi: 10.1201/b18900-7, 115-166.

Asibey EOA, Addo PG. 2000. The grasscutter, a promising animal for meat production. In: African perspective, practices and policies supporting sustainable development (Turnham, D., ed). Scandinavian Seminar College, Denmark, in association with Weaver Press Harare. Zimbabwe. www.cdr.dk/sscafrica/asad-gh.ht.m

Banks JW. 1993. Applied veterinary histology. $3^{\text {rd }}$ ed. Mosby Year Book. Inc. St. Louis,

Baptist R, Mensah GA. 1986. Benin and West Africa. The cane rat, farm animal of the future. Wld. Anim. Rev. 60: 2-6.

Bongso TA, Jainudeen MR, Zahrah AS. 1982. Relationship of scrotal circumference to age, body weight and onset of spermatogenesis in goats. Theriogenology. 18 (5): 513-524. doi: 10.1016/0093-691x(82)90184-4.

Dhabale RB. 2007. Studies on post-natal developmental changes in reproductive organs and effects of gonadotrophin releasing hormone on spermatogenesis in native buck (Bidri, Capra hircus). Thesis Submitted to the Sri Venkateswara Veterinary University in Partial Fulfillment of the Requirements for the Award of the Degree of Doctor of Philosophy in the Faculty of Veterinary Science.

Dyce KM, Sack WO, Wensing CJG. 2002. Text book of veterinary anatomy, $3^{\text {rd }}$ edition, Suanders, Pennsylvania. pp. 183-192.

Gofur MR. 2015. Anatomy and histomorphometry of accessory reproductive glands of the Black Bengal buck. Eur. J. Anat. 19: 171-178.

Gupta AN, Singh Y. 1988a. Post-natal development of the testis in goat. National Symposium on Recent Advances in Anatomy of ruminants Reproduction and IIIrd Convention June 23-25, pp. 20.

Happold DCD. 1987. The mammals of Nigeria. Clarendon Press. Oxford. pp. 10-16.

Jori F, Mensah GA, Adjanohoun E. 1995. Grasscutter farming: an example of rational utilization of wildlife. Biodivers. Conserv. 4: 257-265. doi: https://doi.org/10.1007/ BF00055972.
Monadjem A, Taylor PJ, Denys C, Cotterill FP. 2015. Rodents of sub-Saharan Africa: a biogeographic and taxonomic synthesis. Walter de Gruyter GmbH, Berlin, Germany. pp. 1102.

Monteiro JC, Pinto da Matta SL, Predes FS, Rego de Paula TA. 2012. Testicular morphology of adult Wistar rats treated with Rudgea viburnoides (Cham.) Benth. Leaf Infusion. Braz. Arch. Biol. Technol. 55 (1): 101-105. doi: http://dx.doi.org/10.1590/S1516-89132012000100013.

Nishimura S, Okano K, Yasukouchi K, Gotoh J, Tabata S, Iwamoto H. 2000. Testis developments and puberty in the male Tokara (Japanese native) goat. Anim Reprod. Sci. 64: 127-131. doi: 10.1016/s0378-4320(00)00197-4.

Ntiamoa-Baidu Y. 1998. Sustainable use of bush meat. Wildlife development plan: 1998-2003. Wildlife Department, Accra. 6: 78.

Olukole SG, Oyeyemi MO, Oke BO. 2009. Biometrical observations on the testes and epididdymis of the domesticated adult African Greater Cane Rat (Thryonomys swinderianus). Eur. J. Anat. 13 (2): 71-75.

Olukole SG, Oyeyemi MO, Oke BO. 2010. Gonadal and extragonadal sperm reserves of the domesticated adult African Greater Cane Rat (Thryonomys swinderianus). Reprod. biol. 10 (2): 155-158. doi: 10.1016/s1642$431 \times(12) 60057-6$.

Omirinde JO, Olukole SG, Oke BO. 2019. Age-related changes in the testicular and epididymal sperm parameters in the African Greater Cane Rat (Thryonomys swinderianus, Temminck, 1827). Anim. Res. Intern. 16 (1): 3255 - 3264.

Singh I. 2011. Textbook of human histology with colour atlas and practical guide. Sixth edition. Jaypee Brothers Medical Publishers Ltd, New Delhi.

Skinner JD, Smithers RHN. 1990. The mammals of the southern African sub-region. Pretoria Univ. Press. Pretoria.

Soro D, Karamoko Y, Kimse M, Fantodji A. 2014. Study of basic haematological parameters: indicators of the general state and immune competence in the male grasscutter (Thryonomys swinderianus, Temminck, 1827) bred in captivity in Côte d'Ivoire. J. Anim. Plant Sci. 22 (1): 3379-3387. 